Research, Society and Development, v. 9, n. 3, e125932648, 2020

(CC BY 4.0) | ISSN 2525-3409 | DOI: http://dx.doi.org/10.33448/rsd-v9i3.2648

\title{
A educação para o trânsito: uma temática a ser trabalhada na experimentação em química
}

Traffic education: a theme to be worked on in experimentation in chemistry

Educación vial: un tema para trabajar en la experimentación química

Recebido: 28/01/2020 | Revisado: 11/02/2020 | Aceito: 14/02/2020 | Publicado: 27/02/2020

\section{Everaldo Antônio Goi}

ORCID: https://orcid.org/0000-0003-1952-4202

Universidade Federal de Pelotas, Brasil

E-mail: goi.canoas@gmail.com

Mara Elisângela Jappe Goi

ORCID: https://orcid.org/0000-0002-4164-4449

Universidade Federal do Pampa, Brasil

E-mail: maragoi28@gmail.com

\section{Resumo}

Este trabalho apresenta o tratamento da temática Educação para o Trânsito desenvolvida com alunos de $3^{\circ}$ Ano do Ensino Médio em uma escola privada de ensino. Tem por objetivo trabalhar com questões pertinentes à temática Educação para o Trânsito e o bafômetro, relacionada ao conteúdo de funções orgânicas, bem como a conscientização dos alunos sobre o assunto. A produção de dados ocorreu a partir das atividades desenvolvidas no laboratório de Química, das reflexões sobre a prática realizada por meio da transcrição dos áudios. A partir da transcrição das falas foi realizada à Análise de Conteúdo de Bardin e emergiram as seguintes categorias: (i) Reflexão do experimento como ação positiva aos futuros motoristas; (ii) Potencialidade do uso da experimentação na Educação Básica; (iii) O trabalho com temáticas na Educação Básica. A análise dos dados infere que o tratamento de temáticas sociais promove uma aprendizagem reflexiva e contribuiu para a construção de conceitos de Química.

Palavras-chave: Temática; Experimentação; Bafômetro.

\footnotetext{
Abstract

This work presents the treatment of the theme Education for Traffic developed with students of the 3rd year of high school in a private school. It aims to work with issues relevant to
} 
Traffic Education and Breathalyzer, including the content of organic functions, as well as students' awareness of the subject. The production of data occurred from the activities of the chemistry laboratory, from reflections on the practice performed through the transcription of audios. From the transcription of the speeches, it was carried out in Bardin's Content Analysis and emerged as the following categories: (i) Reflection of the experiment as a positive action for future drivers; (ii) Potentiality of using experimentation in Basic Education; (iii) Work with themes in Basic Education. An analysis of the data infers that the treatment of social themes promotes reflective learning and contributes to the construction of Chemistry concepts.

Keywords: Thematic; Experimentation; Breathalyzer.

\section{Resumen}

Este trabajo presenta o trata la educación temática o el tráfico, realizada con parte del 3er año de la escuela secundaria en una escuela privada. Me temo que el objetivo es trabajar con las preguntas pertinentes sobre el tema Educación o Tráfico y Baómetro, relacionadas con el contenido de las funciones orgánicas, así como hacer que dos estudiantes tomen conciencia del tema. En la producción de datos de actividades que no son de laboratorio en Química, reflexiona sobre la práctica llevada a cabo durante dos años de transcripción. A partir de la transcripción de los discursos, se llevó a cabo en el Análisis de contexto de Bardin y surgirá en las siguientes categorías: (i) La reflexión experimenta una acción positiva para los conductores futuros; (ii) Potencial para el uso de Experimentación en Educación Básica; (iii) Trabajo temático en Educación Básica. Además, analice dos inferencias de datos que aborden problemas sociales, promuevan el aprendizaje reflexivo y contribuyan a la creación de consejos de química.

Palabras clave: Temático; Experimentación; Alcoholímetro.

\section{Introdução}

Segundo Bacchieri \& Barros (2011, p. 950), o Brasil é "considerado um dos países com o trânsito mais violento do mundo". Assim, é necessário desde a Educação Básica tratar sobre esta temática, com o objetivo de formar cidadãos mais conscientes sobre a importância em não dirigir sob o efeito de bebidas alcoólicas (Pinsky \& Pavarino Filho, 2007).

Na Educação Básica, mais precisamente no $3^{\circ}$ Ano do Ensino Médio e na Educação de Jovens e Adultos (EJA) são trabalhadas as funções orgânicas, sendo que uma dessas funções é 
(CC BY 4.0) | ISSN 2525-3409 | DOI: http://dx.doi.org/10.33448/rsd-v9i3.2648

denominada Álcoois. Esses alunos podem desenvolver além do conteúdo de Química, pesquisas que tratam do funcionamento do bafômetro, até mesmo o uso abusivo de álcool na sociedade e seus malefícios, com isso trabalhando com temáticas relevantes do contexto social.

Trabalhar com temáticas no Ensino de Química pode favorecer os processos de ensino e de aprendizagem e propiciar a formação crítica dos estudantes, atuando de forma consciente na sociedade em que estão inseridos. De forma semelhante, são propostos pelos Parâmetros Curriculares Nacionais para o Ensino Médio (PCNEM) (BRASIL, 2000) na área de Ensino de Ciências da Natureza para a Educação Básica, a proposição da formação de cidadãos conscientes dos problemas do cotidiano.

É importante lembrar que desde o ano de 2008 a Lei Seca torna-se mais rígida em relação à tolerância de níveis de álcool no sangue de motoristas, que considera o ato de beber e dirigir como um crime. Assim, busca-se a redução do número de infratores e do número de acidentes de trânsito e, consequentemente, de mortos e feridos decorrentes deste tipo de acidente (Bacchieri \& Barros, 2011).

Uma das maneiras de identificar os usuários de bebida alcóolica é através do instrumento denominado bafômetro. Este aparelho mede a concentração de álcool etílico na corrente sanguínea de uma pessoa mediante análise do ar expelido durante a respiração. Todos os tipos de bafômetros são baseados em reações químicas, e os reagentes mais comuns utilizados para o seu funcionamento são dicromato de potássio e célula de combustível. A diferença entre estes dois reagentes é que o dicromato muda de cor na presença do álcool enquanto a célula gera uma corrente elétrica. $\mathrm{O}$ mais usado pelos policiais no Brasil é o de Célula de combustível. Seu funcionamento ocorre desta forma: I- O álcool expirado reage com a célula de combustível; ii- Ocorre a liberação de elétrons; iii- Os elétrons, então, passam por um fio condutor, gerando corrente elétrica. Um chip presente no aparelho calcula a porcentagem e dá a concentração de álcool no sangue. Quanto mais álcool, maior será a corrente elétrica.

$\mathrm{Na}$ escola, durante as atividades de Química, muitas vezes a identificação de álcool durante as aulas experimentais é realizada através de um bafômetro comum de dicromato de potássio. Através deste experimento os estudantes compreendem a presença de álcool mediante a análise de ar pulmonar e a mudança de cor na reação química.

As aulas experimentais servem como potencializadoras para trabalhar os conteúdos de Química, bem como, oportuniza situações de investigação aos alunos, para isso deve ser bem planejado, desmistificando o trabalho científico e aproximando-o do universo de experiência 
do aluno. Além disso, é necessário encontrar maneiras de usar as atividades experimentais com propósitos bem definidos (Borges, 2002). A efetividade destas atividades dependerá não somente do educador que mediará este processo, mas principalmente do educando que determinará o seu engajamento (Goi, 2004).

O experimento didático foi realizado em uma escola privada de ensino, do município de Porto Alegre/ RS, com o objetivo em trabalhar com questões pertinentes à temática trânsito e bafômetro, relacionada ao conteúdo de funções orgânicas, bem como com a conscientização dos alunos sobre a importância em tratar desta temática na Educação Básica.

\section{Referencial teórico}

\subsection{A experimentação no Ensino de Química}

As práticas de laboratório podem favorecer questões importantes para a construção e o entendimento da ciência. Essas atividades para serem potencializadoras de conhecimento podem estar permeadas por objetivos definidos, oportunizando direção e sentido ao estudo que está sendo realizado. Assim, os alunos conseguem construir hipóteses, analisar dados, observar criticamente os problemas de interesse e implicações da própria Ciência (Borges, 2002).

A organização de uma proposta de ensino balizada por estratégias experimentais pode contribuir para a melhoria da compreensão de conceitos da área de Ciências da Natureza. Segundo Axt (2002), a experimentação pode contribuir para aproximar o Ensino de Ciências das características de um trabalho científico, como também pode colaborar para a aquisição de conhecimento e para o desenvolvimento mental dos alunos.

Na visão de Machado (2002), o ensino experimental quando for bem planejado pode priorizar situações de investigação aos alunos. Assim, a ciência escolar deve privilegiar o ensinar, o fazer e o pensar, estudar os conhecimentos já estruturados e normativos do currículo de acordo com os valores da escola, onde os estudantes pensarão de forma mais autônoma e crítica, sendo a atividade científica escolar o resultado da interação entre o conhecimento, o professor e o aluno, elementos básicos de um sistema didático (Izquierdo \& Espinet, 1999).

González (1992) ressalta que as práticas de laboratório podem favorecer questões fundamentais para o entendimento da Ciência. Segundo o autor, essas atividades serão consistentes quando o aluno estiver preparado para desenvolvê-las, oportunizando direção e sentido ao estudo que está sendo realizado. Nesta situação a experimentação deve ser 
investigativa e a cargo do próprio aluno.

Nessa perspectiva, é relevante que os estudantes possam refletir a partir do experimento que está sendo realizado, portanto o experimento pode servir como um método para compreender os conceitos e não simplesmente reproduzir a ciência, assim as atividades de cunho investigativo relacionado com uma temática social são fundamentais para uma melhor estruturação do laboratório didático (Bassoli, 2014).

\subsection{A temática trânsito na Educação Básica}

A Educação para o Trânsito pode ser aplicada na Educação Básica, desenvolvida simultaneamente ao currículo escolar. Essa temática objetiva compreender os processos de circulação de pessoas e veículos tanto em áreas urbanas como em áreas rurais, que envolvam deslocamentos humanos e de mercadorias, promovendo os vínculos com a Educação para Trânsito, com os direitos humanos e éticos (Seffener \& Schäffer, 2002).

Apesar da temática transversal "trânsito" não estar explicita nos Parâmetros Curriculares Nacionais (PCN), ela é relevante, busca um ensino voltado para a cidadania e que os jovens consigam refletir sobre sua importância, aos agravos à saúde, associados à causas externas como os acidentes extradomiciliares, os riscos decorrentes da violência social, vezes associadas ao uso abusivo de álcool(Goi, Goi \& Steigleder, 2019).

A temática Educação para o Trânsito está de acordo com os PCNs e os seus critérios, tendo quatro dimensões fundamentais para serem consideradas para o tema poder ser trabalhado de forma transversal, são eles:1) Urgência social; 2) Abrangência Nacional; 3) Possibilidades de ensino e de aprendizagem na Educação Básica; 4) Favorecimento e compreensão da realidade e da participação do social (Brasil,1997).

Referente à urgência social, o trânsito há tempo é um problema social, relativamente grave, pois a cada ano morrem em média 50 mil pessoas e outras 350 mil sofrem com sequelas graves. Isso faz com que o Brasil fique em $4^{a}$ posição no rancking mundial de vítimas, com um índice de 22 mortes a cada $100 \mathrm{mil} / \mathrm{hab}$. Desse modo, envolve questões sociais de dimensões puramente técnicas, isso reflete os sérios problemas da organização social do Brasil (Bacchieri \& Barros, 2011). Na visão desses autores a relação entre:

[...] álcool e acidentes de trânsito está bem documentada na literatura internacional e é uma das principais causas de morbimortalidade, atingindo, sobretudo, homens jovens. O "I Levantamento Nacional Domiciliar sobre Padrões de Consumo de Álcool", realizado em 143 cidades brasileiras em 2009, indicou prevalência de 35\% 
de beber e dirigir (43\% para homens e 9\% para mulheres). Entre 2005 e 2009, estudos que relacionaram uso de álcool e vítimas fatais no Estado de São Paulo, Distrito Federal e Porto Alegre encontraram alcoolemia positiva em 45\%, $43 \%$ e $32 \%$ dos casos, respectivamente. Entre vítimas não fatais atendidas em centros de atenção ao trauma e emergências de São Paulo e Uberlândia (MG), a prevalência de ingestão de álcool foi, respectivamente, $24 \%$ e $29 \%$. Cerca de $17 \%$ das vítimas de AT atendidas em serviços de emergência de cidades cobertas pelo Sistema de Vigilância de Violências e Acidentes em Serviços Sentinelas apresentavam suspeita de uso de álcool. (Bacchieri \& Barros, 2011, p.953).

O tema "trânsito" pode ser trabalhado para promover a interação das disciplinas do currículo escolar, pois é complexo e envolve questões éticas, culturais, políticas, econômicas, técnicas, físicas e sociais. Então, para ser abordada requer esforço para compreender como os diferentes saberes se relacionam promovendo uma aprendizagem relevante, que discuta aspectos reais da Educação para o Trânsito e promova a reflexão das práticas cotidianas e da relação com outros atores da circulação. Assim, a compreensão da temática "trânsito" atende ao terceiro e quarto critério estabelecido pelos PCNs, ou seja, a possibilidades de ensino e de aprendizagem na Educação Básica e o favorecimento e compreensão da realidade e da participação social. Desse modo, durante a vida escolar o aluno vai experimentando novos modelos de circulação, alterando sua percepção do trânsito, aperfeiçoando seu conhecimento sobre mobilidade e circulação.

O acesso à Educação para o Trânsito é um direito de todos previsto na Constituição Federal e constitui dever prioritário para do Sistema Nacional de Trânsito. Segundo a Constituição Federal de 1988 "É competência comum da União, dos Estados, do Distrito Federal e dos Municípios: XII estabelecer e implantar política de educação para a segurança do trânsito.” Porém, percebe-se que essa educação deve ser iniciada durante a trajetória do cidadão no âmbito escolar e não apenas ao ingressar na vida adulta, tampouco apenas quando for se habilitar, no Brasil, a partir dos dezoito anos de idade.

Nessa ótica, a escola pode tratar de questões que incentivem a promoção à vida tratando de valores fundamentais para a educação. Nota-se que existe a preocupação dos órgãos reguladores de trânsito (Departamento Estadual de Trânsito -DETRAN, Departamento Nacional de Trânsito -DENATRAN e o Conselho Nacional de Trânsito -CONTRAN) que entendem da importância da Educação para o Trânsito. Esses departamentos promovem projetos que buscam a formação na Educação Básica e em cursos de legislação de trânsito para qualificar os instrutores de trânsito (Vizzotto, Mackedanz \&Miranda, 2017).

Vizzotto, Mackedanz \& Miranda (2017) evidenciaram em sua pesquisa a preocupação da escola e dos departamentos de trânsito com a prevenção de acidentes, sobretudo, com 
mortes. Os autores apontam um aumento anual do número de acidentes e fatalidades, sendo a maioria das mortes entre jovens que recentemente saíram da Educação Básica. Nesse sentido, é importante lembrar que o Código de Trânsito Brasileiro desde que entrou em vigor, no ano de 1998, compreende que é necessário educar as crianças e jovens para que a próxima geração seja mais consciente ao se inserir no trânsito. Apesar de alguns hábitos terem mudado (ex. uso do cinto de segurança), algumas práticas continuam sendo reproduzidas, como, exceder limites de velocidade e dirigir sob efeito de bebidas alcoólicas, o que mantém os altos índices de mortes e feridos no trânsito.

\section{Metodologia e contexto da pesquisa}

Esta pesquisa foi realizada em uma escola privada de ensino localizada no município de Porto Alegre com 13 estudantes entre 16 a 18 anos de idade do $3^{\circ}$ Ano do Ensino Médio. Para resguardar a identidade dos estudantes serão denominados pela letra A, seguida da numeração de 1 a 13 (A1....A13).

Para a produção de dados desta pesquisa foi tratada a temática Educação para o Trânsito versus bafômetro na sala de aula, bem como foi realizado um experimento sobre a identificação de álcool no organismo humano e aplicado um questionário, com o objetivo de mapear o que os estudantes sabem sobre a temática. Os responsáveis e/ou alunos assinaram um Termo de Consentimento Livre e Esclarecido para que os pesquisadores pudessem dar continuidade à pesquisa.

Neste artigo foi realizado um recorte dos dados da pesquisa analisando a atividade de construção do bafômetro, para isso foram gravados os áudios das aulas e posteriormente analisadas pela Análise de Conteúdo de Bardin (2011), que consiste em saber por qual razão se analisa e se explicita, de modo que se possa saber como analisar. Tratar o material é codificá-lo a partir dos dados brutos do texto, através de recortes, agregações, enumerações que permitem atingir uma representação de conteúdo ou de sua expressão. Para Bardin (2011), a organização da codificação compreende três escolhas: o recorte (escolha das unidades), a enumeração (escolha das regras de contagem) e a classificação e agregação (escolha das categorias). A partir da transcrição dos áudios emergiram as seguintes categorias de análise: (i) Reflexão do experimento como ação positiva aos futuros motoristas; (ii) Potencialidade do uso da experimentação na Educação Básica; (iii) O trabalho com temáticas na Educação Básica.

A atividade experimental foi similar ao artigo de Ferreira, Mól \& Silva (1997) quando 
Research, Society and Development, v. 9, n. 3, e125932648, 2020

(CC BY 4.0) | ISSN 2525-3409 | DOI: http://dx.doi.org/10.33448/rsd-v9i3.2648

demostram um modelo de Bafômetro. A prática pode ser visualizada no quadro abaixo:

Quadro 1: Materiais para produção do Bafômetro

\begin{abstract}
- 4 balões de cores diferentes; $\bullet 4$ pedaços de tubo plástico transparente de $10 \mathrm{~cm}$ de comprimento; $\bullet 2$ barras de giz escolar; •4 rolhas; • algodão; • solução ácida de dicromato de potássio que deve ser preparada da seguinte forma: em $40 \mathrm{~mL}$ de água adicione vagarosamente $10 \mathrm{~mL}$ de ácido sulfúrico concentrado e $1 \mathrm{~g}$ de dicromato de potássio. Agite o sistema a fim de que a solução fique homogênea (cuidado ao manusear o ácido sulfúrico, pois a diluição do ácido sulfúrico concentrado é um processo altamente exotérmico e libera calor suficiente para causar queimaduras). Ao preparar soluções diluídas a partir do ácido concentrado, sempre adicione o ácido à água lentamente, agitando continuamente a solução.
\end{abstract}

Fonte: Ferrreira, Mól \& Silva (1997)

Quadro 2: Procedimentos para a construção do Bafômetro.

Quebre o giz em pedaços. Coloque os fragmentos em um recipiente e a seguir molhe-os com a solução de dicromato, de maneira que fiquem úmidos, mas não encharcados. Com o auxílio de um palito, misture os fragmentos de giz colorido pela solução de forma que o material fique com uma cor homogênea. Esse material deve ser usado após o preparado. Coloque pequenos pedaços de algodão em cada um dos tubos e em seguida coloque as rolhas do lado em que se coloca o algodão. Em seguida, coloque mais ou menos a mesma quantidade de pedaços de giz tubos. Então, coloque $0,5 \mathrm{~mL}$ (cerca de 10 gotas) de aguardente no balão $\mathrm{n}^{\circ} 2,0,5 \mathrm{~mL}$ de vinho no balão $\mathrm{n}^{\mathrm{o}} 3,0,5 \mathrm{~mL}$ de cerveja no balão $\mathrm{n}^{\mathrm{o}} 4$; no balão $\mathrm{n}^{\circ} 1$ não coloque nada, pois ele é o controle do experimento. Encha os balões com mais ou menos as mesmas quantidades de ar e depois coloque-os nos tubos previamente preparados. Iniciando pelo balão $\mathrm{n}^{\mathrm{o}} 1$, solte o ar lentamente, soltando a rolha. Proceda da mesma forma com os balões restantes. Espere o ar sair dos balões e compare a alteração da cor nos tubos. A seguir, ordene os tubos 2 a 4 em função da intensidade de mudança de cor (alaranjado para azulado).

Fonte: Ferrreira, Mól \& Silva (1997)

Após o experimento os alunos foram instigados a refletir sobre a ação do álcool no organismo humano, como também da importância em tratar desta temática desde o início da escolarização, seja através de projetos desenvolvidos pelas escolas ou de acordo com os conteúdos tratados nos componentes curriculares.

\title{
4. ANÁliSE E DISCUSSÃo DE RESULTADOS
}

(i) Reflexão do experimento como ação positiva aos futuros motoristas

A construção do bafômetro não emergiu da proposta da professora da turma. Primeiramente os alunos estavam trabalhando com a função orgânica álcool na disciplina de 
Química e a partir das discussões sobre os malefícios que a substância álcool causa no organismo humano os estudantes iniciaram vários questionamentos sobre a temática e pesquisaram sobre como identificar esta função. Essa pesquisa gerou o aprofundamento teórico das quantidades de álcool detectadas em humanos e da forma com que pode ser identificada nos motoristas que circulam embriagados.

O Experimento que os alunos propuseram no laboratório de Química não foi inovador, pois já é descrito na literatura, mas serviu para que os estudantes pesquisassem práticas de laboratório que envolvesse a temática, isso porque a professora não forneceu o roteiro préestabelecido. Desta forma os alunos pesquisaram diferentes formas de fazer uma prática que envolvesse a construção do bafômetro e isso promoveu a autonomia do aluno no contexto escolar. Além disso foi uma atividade que proporcionou o debate de questões sociais com o objetivo de refletir sobre o uso abusivo de álcool e o trânsito.

No bafômetro produzido no laboratório de Química os alunos puderam conhecer o funcionamento do aparelho e visualizar a presença de álcool em cada bebida, servindo também de alerta, pois muitos alunos desta turma estão prestes a completar 18 anos de idade e pretendem ingressar, ainda nos próximos meses, em uma autoescola e muitos desses já tem uma opinião formada, como na fala da aluna A1 a seguir: "Um pouco de álcool no sangue faz a pessoa ficar diferente. Eu não bebo, mas tenho que me preocupar com quem bebe” (A1). A mesma opinião é compartilhada com outro aluno de 18 anos: “A lei é uma forma de educar os motoristas" (A2). A estudante A3 revela que "É importante implementar a Lei Seca no país, porque muitas tragédias podem ser evitadas no trânsito". Já o estudante A4 enfatiza que:” Os motoristas precisam entender de uma vez por todas que álcool e direção não combinam”. Os quatro excertos apontam que trabalhar com a Educação para o Trânsito na escola é uma ação positiva para que diminua as ocorrências nos futuros motoristas e que possam falar sobre essas ações com seus familiares e amigos. Assim, é relevante que escolas e departamentos envolvidos em Educação para o Trânsito promovam projetos que visem a formação desde a Educação Infantil ao Ensino Médio, como também cursos de legislação de trânsito e requalificação didática para os instrutores de trânsito (Vizzotto, Mackedanz \& Miranda, 2017).

As ações desenvolvidas por este grupo de alunos tiveram continuidade. Durante as atividades desenvolvidas visualizaram documentários sobre a relação de álcool e volante, ouviram e participaram de palestras com agentes da Empresa Pública de Transporte e Circulação (EPTC), dentro de um projeto de valorização da vida desenvolvido pela própria escola. Essas atividades vêm ao encontro do que os autores Vizzotto, Mackedanz \& Miranda 
(2017) constatam em sua pesquisa, quando apontam a importância das iniciativas nas escolas e nos departamentos de trânsito com a prevenção de mortes em acidentes de trânsito.

\section{(ii) Potencialidades do uso da experimentação na Educação Básica}

A experimentação é uma estratégia metodológica utilizada nos vários níveis de ensino. Nesta experiência didática, a experimentação promoveu além do trabalho com o conteúdo de oxirredução tratado em Química e o trabalho com a função orgânica Álcoois, a reflexão dos estudantes em prol de um tema social bastante polêmico: A Educação para o Trânsito.

A atividade experimental desenvolvida cumpriu seu papel no quesito de atividade investigativa, pois os alunos foram além de identificar a presença de álcool através do experimento tradicional. Foram os alunos que pesquisaram a atividade que iriam desenvolver para identificar a presença de álcool em algumas bebidas. Sabe-se que chegaram em uma atividade já trabalhada nas aulas de Química, mas o diferencial deste trabalho foram os alunos, que pesquisaram o experimento, conduziram a prática e discutiram os resultados em plenária no laboratório de Química. Assim, a atividade experimental não foi inovadora, mas a forma com que foi conduzida promoveu a autonomia dos estudantes. Isso já foi visualizado em outros trabalhos quando o professor consegue dar voz ao aluno para conduzir a sua própria prática no laboratório, os mesmos conseguem ter uma visão diferenciada da prática realizada, pois são eles que organizam o material, criam as hipótese, traçam as metas, levantam possíveis resultados e chegam a uma resposta ( Goi, 2004).

A atividade prática desenvolvida instigou os estudantes construir as hipóteses, analisar dados, observar criticamente os problemas de interesse e implicações da própria Ciência, como já apontado por Borges (2002). Além disso promoveu um debate com profissionais da área (EPCT) sobre a importância em não dirigir embriagado e sobre os danos que podem causar a outras pessoas. Deste modo, a atividade desenvolvida no laboratório foi além do experimento, promoveu a reflexão social e levantou questões da polêmica da temática estudada.

Para Bassoli (2014) o experimento deve servir como um método para compreender os conceitos e não simplesmente reproduzir a ciência, assim as atividades de cunho investigativo relacionado com uma temática social são fundamentais para uma melhor estruturação do laboratório didático. Nesse sentido, este trabalho promoveu o debate através de uma aula experimental de Química e conduziu à escola a promover ações desafiadoras, que vai além do trabalho com conteúdo mínimo de cada componente curricular. 


\section{(iii) O trabalho com temáticas na Educação Básica}

O uso de temáticas no Ensino de Química pode favorecer a qualificação dos processos de ensino e de aprendizagem, além de promover a formação dos estudantes para que estes atuem de forma consciente no meio social em que estão inseridos. Os Parâmetros Curriculares Nacionais para o Ensino Médio (PCNEM) (Brasil, 2000) no âmbito do Ensino de Ciências da Natureza para a Educação Básica, propõe a formação dos alunos balizados em problemas do cotidiano e embasados por temáticas. Deste modo, esta experiência didática oportunizou aos alunos o trabalho com uma temática relevante no meio social e as discussões de qualidade de vida para os cidadãos brasileiros. Esse tipo de trabalho já foi demonstrado que tem potencial por Halmenschlager (2014), Hunsche (2015), da Silva \& Goi (2019).

Halmenschlager (2014) defende a estruturação dos currículos escolares embasados em temáticas. Esses, por sua vez, devem estar de acordo com a realidade dos estudantes, bem como a utilização de temáticas no ensino é justificada pela minimização da fragmentação e linearidade dos conteúdos escolares em defesa da contextualização e interdisciplinaridade, de acordo com o que é proposto nas DCNs.

Em um estudo realizado por Goi, Goi \& Steigleder (2019) sobre a implementação de temáticas por professores de Ciências da Natureza em escolas da região sul do Brasil, ressaltase que os professores argumentam que ao planejarem suas aulas utilizam alguma temática para construção de projetos curriculares. Assim, nota-se que temáticas, mesmo não sendo apenas "Educação para o Trânsito" são tratadas nas escolas. Isso, talvez se deva por estar descrito na proposta das DCNs (Brasil, 2012), ao achar relevante a um ensino contextualizado, de maneira a ter significado no aprendizado do estudante. Esse debate também é apontado na Base Nacional Comum Curricular- BNCC (2017), como revelam Da Silva \& Goi (2019, p.2):

As temáticas relacionadas a problemas cotidianos estão cada vez mais presentes no ambiente escolar, tornando-se imperativo entender como elas vem sendo abordadas na Educação Básica. A diversidade de temas, assuntos ou tópicos utilizados como meio de aproximação do conhecimento no ensino das diferentes áreas dos saberes tem ganhado espaço nos currículos escolares, embasados principalmente pelos documentos oficiais que norteiam a educação brasileira. A exemplo disso, a Base Nacional Comum Curricular para o Ensino Fundamental - BNCC (Brasil, 2017), orienta a adoção pelas redes de ensino, de propostas pedagógicas que contemplem a abordagem de temas contemporâneos, presentes no cotidiano humano em escala regional e global, preferencialmente de forma transversal e integradora. 
A questão do trânsito na Educação Básica é um desafio para os professores e profissionais que se envolvem com os processos de ensino e de aprendizagem, bem como, que tratam de temáticas no currículo escolar, que se preocupam com a formação de cidadãos críticos que objetivam trabalhar e viver na sociedade em que estão inseridos em prol da coletividade. Na ótica de Vizzotto, Mackedanz \& Miranda (2017, p.139) “É preciso compreender criticamente o mundo ao redor, os direitos e deveres de condutores e pedestres e a aplicação de conhecimentos de cunho científico, que por mais simples que pareçam ser, podem fazer a diferença no trânsito, principalmente na prevenção de complicações maiores [...]". A partir desta constatação é um desafio aos professores da Educação Básica tratar dos conteúdos escolares relacionados com as temáticas socialmente relevantes, visando uma educação voltada para a cidadania. Com isso espera-se que ao tratar desse assunto, "os jovens consigam refletir sobre os principais agravos à saúde, que muitas vezes estão associados às chamadas causas externas, especialmente relacionados aos acidentes extradomiciliares e aos riscos decorrentes da violência social" (Goi, Goi \& Steigleder, 2019).

\section{Considerações finais}

O objetivo desta pesquisa foi trabalhar com questões pertinentes à temática trânsito e bafômetro, relacionada ao conteúdo de funções orgânicas, bem como com a conscientização dos alunos sobre a importância em tratar desta temática na Educação Básica. A partir dos dados produzidos e analisados, destaca-se que o trabalho com temáticas sociais é relevante, pois vai além do tratamento curricular do conteúdo. Envolve reflexão, ação e mudança na forma com que os cidadãos veem o problema que assola a sociedade.

Destaca-se de forma geral que o tratamento desta temática contribuiu para que os estudantes conhecessem melhor o assunto, se apropriassem do conteúdo químico, percebessem a relevância da organização e elaboração da pesquisa na escola, bem como, da relevância do desenvolvimento de atividades experimentais que privilegiem a adoção de conceitos científicos associados a demandas sociais.

\section{Referências}

Axt, R. (2002). O Papel da Experimentação no Ensino de Ciências. Disponível em Acesso em: 18 set.2019. 
Bacchieri, G., \& Barros, A. J. (2011). Acidentes de trânsito no Brasil de 1998 a 2010: muitas mudanças e poucos resultados. Revista de Saúde Pública, 45(5), 949-963.

Bardin, L. (2011). Análise de conteúdo. São Paulo: Edições 70. Brasil.(2014a). Manual de enfrentamento à violência contra a pessoa idosa. Brasília: Secretaria de Direitos Humanos da Presidência da República.

Bassoli, F. (2014). Atividades práticas e o ensino-aprendizagem de ciência (s): mitos, tendências e distorções. Ciência \& Educação (Bauru), 20(3), 579-593.

Borges, A. T. (2002). Novos rumos para o laboratório escolar de ciências. Caderno Brasileiro de Ensino de Física, 19(3), 291-313.

Brasil, M. E. C. (1997). Parâmetros curriculares nacionais. Brasília, DF: MEC/SEF.

Brasil, M. E. C. (2000). Parâmetros Curriculares Nacionais para o Ensino Médio. Brasília, $D F: M E C / S E F$.

Brasil. (2012). Resolução no 2, de 30 de janeiro 2012. Define Diretrizes Curriculares Nacionais para o Ensino Médio.

da Silva, É. R. A., \& Goi, M. E. J. (2019). Articulação entre Resolução de Problemas e a temática drogas como proposta metodológica para o Ensino de Química. Revista Contexto \& Educação, 34(107), 104-125.

da Silva, É. R. A., \& Goi, M. E. J. (2019). ARTICULAÇÃO ENTRE RESOLUÇÃO DE PROBLEMAS E TEMÁTICAS NO ENSINO DE CIÊNCIAS: UMA ANÁLISE EM PERIÓDICOS DA ÁREA. VIDYA, 39(1), 195-214.

Ferreira, G. A., Mól, G. D. S., \& Silva, R. D. (1997). Bafômetro: um modelo demonstrativo. Química nova na escola, (5), 32-33.

Goi, M. E. J. (2004). A Construção do conhecimento químico por estratégias de Resolução de Problemas. 
Goi, E. A., Goi, M. E. J., \& Steigleder, N. EDUCAÇÃO PARA O TRÂNSITO NA EDUCAÇÃO BÁSICA.

González Eduardo, M. (1992). ¿ Qué hay que renovar en los trabajos prácticos?. Enseñanza de las Ciencias, 10(2), 206-211.

Halmenschlager, K. R. (2014). Abordagem de temas em Ciências da Natureza no Ensino Médio: implicações na prática e na formação docente.

Hunsche, S. (2016). Docência no ensino superior: abordagem temática nas licenciaturas da área de ciências da natureza.

Izquierdo, M., Sanmartí, N., \& Espinet, M. (1999). Caracterización y diseño de las prácticas escolares deficiencias experimentales. Enseñanza de las Ciencias, 17(1), 79-92.

Machado, J. R. C. (2002). Considerações sobre o ensino de química. UFPA EduquimDisponível em: < http://www. ufpa. br/eduquim/consideracoes. htm>. Acessado em, 9.

Pinsky, I., \& Pavarino Filho, R. V. (2007). A apologia do consumo de bebidas alcoólicas e da velocidade no trânsito no Brasil: considerações sobre a propaganda de dois problemas de saúde pública. Revista de Psiquiatria do Rio Grande do Sul, 29(1), 110-118.

Seffner, F., \& Shãffer, N. O. (2002). A educação para o trânsito como conteúdo permanente no currículo escolar. Trânsito e Educação: Itinerários pedagógicos. Porto Alegre: UFRGS Editora, 17-25.

Vizzotto, P. A., Mackedanz, L. F., \& Miranda, A. C. D. (2017). Física aplicada ao trânsito: uma revisão de literatura. Revista Thema, 14(1), 137-163.

\section{Porcentagem de contribuição de cada autor no manuscrito}

Everaldo Antônio Goi - 50\%

Mara Elisângela Jappe Goi - 50\% 